\title{
Historical and Current Concepts of Fibrillogenesis and In vivo Amyloidogenesis: Implications of Amyloid Tissue Targeting
}

\author{
Robert Kisilevsky ${ }^{1 *}$, Sara Raimondi ${ }^{2}$ and Vittorio Bellotti ${ }^{2,3}$ \\ ${ }^{1}$ Department of Pathology and Molecular Medicine, Queen's University, Kingston, ON, Canada, ${ }^{2}$ Unit of Biochemistry, \\ Department of Molecular Medicine, University of Pavia, Pavia, Italy, ${ }^{3}$ Wolfson Drug Discovery Unit, Division of Medicine, \\ Centre for Amyloidosis and Acute Phase Proteins, University College London, London, UK
}

\section{OPEN ACCESS}

Edited by:

Vladimir N. Uversky,

University of South Florida, USA

Reviewed by:

Leonid Breydo,

University of South Florida, USA

Olga Gursky,

Boston University School of Medicine,

USA

*Correspondence:

Robert Kisilevsky

kisilevr@queensu.ca

Specialty section:

This article was submitted to

Protein Folding, Misfolding and

Degradation,

a section of the journal

Frontiers in Molecular Biosciences

Received: 22 March 2016

Accepted: 21 April 2016

Published: 09 May 2016

Citation:

Kisilevsky R, Raimondi S and Bellotti V

(2016) Historical and Current

Concepts of Fibrillogenesis and In vivo

Amyloidogenesis: Implications of

Amyloid Tissue Targeting

Front. Mol. Biosci. 3:17

doi: 10.3389/fmolb.2016.00017
Historical and current concepts of in vitro fibrillogenesis are considered in the light of disorders in which amyloid is deposited at anatomic sites remote from the site of synthesis of the corresponding precursor protein. These clinical conditions set constraints on the interpretation of information derived from in vitro fibrillogenesis studies. They suggest that in addition to kinetic and thermodynamic factors identified in vitro, fibrillogenesis in vivo is determined by site specific factors most of which have yet to be identified.

Keywords: historical perspectives, in-vivo/in-vitro comparisons, site specific amyloid tissue deposition

\section{INTRODUCTION}

Until relatively recently "amyloid" was considered to be a relatively rare and esoteric medical entity. A "Pubmed" search of the term "amyloid" by decade indicates but two publications for the period 1921-1930 and eight for 1931-1940. This increase in number accelerated over the next four decades and reached $\sim 25,000$ for the period 2001-2010. Given the number of publications for 2011-2015 the projected result for 2011-2020 is of the order of 50,000 (Figure 1). Furthermore, amyloid involvement in common disorders such as Alzheimer's disease and type 2 diabetes as well as forms (e.g., prions) that may be transmitted through our food supply have made it a subject of interest to diverse clinicians and basic scientists (Figure 2). Most importantly existing therapeutic modalities that prevent continuous amyloid deposition allows the mobilization of existing deposits with clinical improvement. Such observations indicate that amyloid does turn over and its presence in tissue has adverse effects on physiological function. Amyloid is not simply a "tombstone" of previous injuries.

The history of "amyloid" as it relates to its composition, structure, and the pathogenetic mechanism of tissue deposition has been the subject of several extensive recent reviews (Sipe and Cohen, 2000; Kyle, 2001; Westermark, 2005). We will focus primarily on more modern concepts that may promote, or potentially confound, future progress. This is particularly true of in vivo amyloidogenesis that occurs at tissue sites remote from the biosynthetic origin of

Abbreviations: AA, amyloid A; $\mathrm{A} \beta$, amyloid-beta; $\mathrm{A} \beta 2 \mathrm{M}$, beta-2-microglobulin amyloid; $\mathrm{AEF}$, amyloid enhancing factor; AIAPP, islet amyloid polypeptide amyloid; AL, immunoglobulin light-chain amyloid; apoAI, apolipoprotein AI; apoE, apolipoprotein E; ATTR, transthyretin amyloid; $\beta 2 \mathrm{M}$, beta-2-microglobulin; GAG, glycosaminoglycan; HDL, high density lipoprotein; HS, heparan sulfate; HSPG, heparan sulfate proteoglycan; IAPP, islet amyloid polypeptide; NMR, nuclear magnetic resonance; SAA, serum amyloid A; SAP, serum amyloid P; TTR, transthyretin. 
the corresponding amyloid precursor protein. For example, in animal models that mimic the form of human amyloid seen after persistent acute inflammation, amyloid is derived from the acute-phase protein serum amyloid A (SAA). This protein is synthesized primarily in the liver but is first deposited in very specific anatomic sites such as the follicular and perifollicular zones of the spleen, which are remote from its site of synthesis (Snow and Kisilevsky, 1985). More remarkably a different amyloidogenic protein, transthyretin (TTR), apparently has different tissue affinities after the substitution of but single amino acids, products of genetic mutations (Benson, 1996; Benson and Uemichi, 1996; Saraiva, 2001). A similar observation has been made recently in the case of beta-2microglobulin ( $\beta 2 \mathrm{M}$; Valleix et al., 2012; Mangione et al., 2013). Why and how does amyloid in vivo get to be deposited at particular cell or tissue sites and does this tell us anything about current concepts that are based on in vitro studies?

\begin{tabular}{|lc|}
\hline Decade & Number of Publications \\
\hline $1921-1930$ & 2 \\
$1931-1940$ & 8 \\
$1941-1950$ & 51 \\
$1951-1960$ & 172 \\
$1961-1970$ & 596 \\
$1971-1980$ & 1376 \\
$1981-1990$ & 3735 \\
$1991-2000$ & 11893 \\
$2001-2010$ & 27491 \\
$2011-2015$ (2020) & 24074 (50000) \\
$\begin{array}{l}\text { FIGURE 1| “Amyloid” publications by decade determined from } \\
\text { pubmed. }\end{array}$
\end{tabular}

\section{PATHOGENESIS OF AMYLOID DEPOSITION IN VIVO}

During the 1890s it was noticed that immunization of horses for the production of diphtheria antisera led to systemic amyloidosis. Rabbits and mice immunized with foreign antigens also developed systemic amyloid deposition. These observations raised the possibility that a disturbance of the immune system played a role in amyloidogenesis. This concept was consistent with clinical and histological observations though no clearly defined mechanism was invoked. In the early 1970s, when this vague immunological idea was still prevalent, experiments were performed to determine whether "immunological memory" (in the sense that the immune system "remembers" previous exposure to defined antigens and reacts much more rapidly on second exposure to the antigen than following the first) played a role in amyloidogenesis (Axelrad et al., 1975, 1982; Axelrad and Kisilevsky, 1980). The results of these investigations inadvertently led to the recognition of a biological property called "amyloid enhancing factor" (AEF) which, on the basis of kinetic data, appeared to function in vivo as a "seed" for fibrillization (Kisilevsky and Boudreau, 1983). Furthermore, in the presence of AEF any acute inflammatory stimulus, immunogenic or not, could very rapidly trigger amyloid deposition of the AA type (Axelrad et al., 1975, 1982; Axelrad and Kisilevsky, 1980). This observation, among others to be considered below, began to question whether an immune process was at the basis of amyloid deposition generally.

\section{AMYLOID COMPOSITION AND STRUCTURE}

It is generally accepted that the first description of organ involvement by what we now consider to be amyloid was made by Nicolaus Fontanus in 1639. Little additional understanding occurred for another 150-200 years. The possibility that lipidlike material was the basic nature of amyloid was implied by the descriptive term "lardaceous" used by Portal, Merat, and

\title{
Amyloid is of Interest to Diverse Basic Scientists and Clinicians
}

\author{
1) Biophysicists - kinetics and thermodynamics of protein folding and fibril assembly \\ 2) Protein Biochemists - protein structure and fibril assembly \\ 3) Biologists - natural amyloid-like fibrils and their possible function \\ 4) Pathologists - accurate diagnosis of diseases in which amyloid plays a role \\ 5) Nephrologists - renal involvement in many forms of amyloid \\ 6) Hematologists - plasma cells, B-cells and their malignancies leading to amyloid \\ 7) Neurologists - degenerative peripheral and CNS disorders associated with amyloids \\ 8) Endocrinologists - amyloids based on misfolded protein hormones \\ 9) Cardiologists - myocardial involvement in many forms of amyloid \\ 10) Radiologists - live imaging techniques studying organs involved by amyloid \\ 11) Veterinarians - pets and zoo animals affected by amyloid \\ 12) Public Health - food sources that carry transmissible forms of amyloid
}

FIGURE 2 | The broad diversity of interests in amyloid. 
Rokitansky in reports of the period 1789-1842 (cf Kyle, 2001). "Amyloid" meaning starch-like (from the Greek "amylon" for starch) was coined by Schleiden in 1838 (cf Kyle, 2001) for botanical purposes and was applied (Virchow, 1854) to organ amyloid based on its positive reaction with iodine in an acidic environment, the chemical reaction being used to identify starch or cellulose. Virchow's interpretation of the positive result was that amyloid was starch-like in nature, which implied that it was a carbohydrate. His conclusion was not completely accurate. Nonetheless, the name persists as does the concept that a carbohydrate is part of amyloid deposits in vivo (discussed below).

Initial histological observations (1859-1920) based on dye interactions with tissue sections suggested that the amyloid deposits were "albuminoid" in nature (Friedrich and Kekule, 1859), namely protein, and possessed no particular organization (cf Kyle, 2001). The development of Congo red in 1883 for use in the textile industry and subsequent use for the staining of tissue sections for microscopy was instrumental in changing this view (Bennhold, 1922). The red/green birefringence observed in Congo red stained tissue sections when viewed in polarized light indicated a very well ordered repetitive super-structure which conferred the characteristic optical properties to amyloid upon its binding of Congo red (Howie et al., 2008; Howie and Brewer, 2009). However, the nature of this structure remained elusive until the 1950s.

The advent of the electron microscope and its application to amyloid tissue deposits (1950s) revealed the fibrillar nature of amyloid (Cohen and Calkins, 1959), changed our concept of its structure and provided a specific direction for amyloid research to follow. The challenge was to isolate these fibrils and then determine the protein responsible for its structure (singular, since at that time amyloid was thought to be the same regardless of its tissue of origin). In the late $1960 \mathrm{~s}$ groups in Israel (Pras et al., 1968; Franklin and Pras, 1969), and Boston (Cohen and Calkins, 1964), developed techniques to liberate fibrils from tissues containing amyloid and it was assumed that the structure of such liberated fibrils (ex vivo fibrils) was identical to those found in situ. This may or may not be true and will be addressed in greater detail below as it bears on several additional concepts and conclusions that are driving current research. Regardless, this technical achievement led to an explosion of information concerning the structure of ex vivo and in vitro fibrils, their composition, identification of the various amyloidogenic peptides and their protein precursors, and characterization of structural modifications and intermediates that occur during the in vitro conversion of the globular precursor into fibrils. It provided the impetus to:

1. determine where and under what conditions biosynthesis of each of the amyloidogenic proteins took place,

2. conduct genetic analyses and distribution of specific forms of amyloidosis in human populations,

3. identify particular mutations that enhance the amyloidogenic potential of the protein concerned, and,
4. develop techniques for the in vitro study of fibrillogenesis to elucidate the kinetics and thermodynamics of protein fibril assembly and the fine structure of such fibrils.

In 1970 the first amyloid protein was isolated from natural deposits occurring in a patient affected by multiple myeloma and amyloidosis. This amyloid protein was composed mainly of a fragment of a monoclonal light chain whose primary structure was identical to the variable region of the monoclonal light chains isolated from the patient's urine (Glenner et al., 1970, 1971a,c). At that time amyloid was still thought to be the same regardless of its clinical setting or tissue of origin, and the observation that an immunoglobulin could form amyloid was consistent with the then prevailing view that amyloid was a product of a derangement in immune function. Additional evidence supporting this idea came from the clinical settings in which amyloid was frequently seen such as persistent infections (e.g., tuberculosis, osteomyelitis), auto-immune diseases (e.g., rheumatoid arthritis or ankylosing spondylitis) and malignancies of the immune system (e.g., multiple myeloma and B-cell dyscrasias). Moreover, the cell types seen in the tissues affected in such diseases were lymphocytes, macrophages, and plasma cells, cells of the immune system. Not surprisingly between the $1890 \mathrm{~s}$ and 1970 the primary concept concerning the pathogenesis of amyloid was a poorly defined disturbance of immune function in which proteolytic fragmentation of the immunoglobulin lightchain led to the deposition of these fragments as amyloid. This conclusion was supported by in vitro studies with Bence-Jones protein (the monoclonal light chain present in urine) which when treated with trypsin generated fibrils that appeared identical to those extracted from tissue (Glenner et al., 1971a; Glenner, 1972). Analysis of these ex vivo fibrils, and those created in vitro, by $\mathrm{X}$ ray diffraction and subsequently infra-red spectroscopy revealed an underlying crossed beta-sheet organization (Glenner et al., 1971b; Harada et al., 1971).

Thus, by the early 1970s, the accumulated data laid the foundation for most of the concepts driving current investigations. A more detailed definition of amyloid was framed: when examined in situ amyloid appeared amorphous with routine stains and light microscopy; amyloid stained with Congo red when viewed in polarized light exhibited red/green birefringence; ultrastructurally amyloid was composed of fibrils; and fibrils extracted from tissue as well as fibrils generated in vitro possessed a characteristic X-ray diffraction pattern. Though pathologists in the 1930's observed subtle staining differences with Congo red between primary (now $\mathrm{AL}$ ) and secondary (now AA) amyloid which suggested an underlying difference in chemical composition, in the late 1960s to early 1970s, amyloid was still considered to be a product of a single protein, likely an immunoglobulin light-chain, and proteolysis was believed to be a critical step in its conversion to fibrils. Furthermore, the fibrils seen ex vivo and those generated in vitro were thought to be identical to those seen in situ.

Substantial progress has been made regarding protein fibril structure since the early 1970's. A large literature is now available which describes the kinetics and thermodynamics of amyloid-like fibril assembly in vitro, and under appropriate in vitro conditions 
virtually any protein has the potential to change conformation and acquire substantial beta-sheet structure (cf Buell et al., 2014). In the last 4-5 years the application of protein magic angle spin solid state NMR to the structural characterization of ex vivo amyloid fibrils from different proteins is providing fundamental atomic details on the structure of amyloidogenic monomers and the type of intermolecular interactions that exist between these monomers (Petkova et al., 2006; Wasmer et al., 2008; Barbet-Massin et al., 2010; Debelouchina et al., 2010, 2013; Comellas et al., 2011; Hellmus et al., 2011). Through solid state NMR in combination with high resolution cryoelectron microscopy and atomic force microscopy the general 3D structure of ex vivo amyloid fibrils is emerging as well as the specific structural differences contributed by the different types of amyloidogenic proteins. Recent work (Lu et al., 2013) on the structure of $A \beta$ amyloid fibrils seeded on $A \beta$ amyloid plaques in brain homogenates attempted to exploit the potency of this technology in revealing subtle but important differences between fibrils obtained in vitro and fibrils grown on a substrate of natural $A \beta$ amyloid plaques, or possibly the extracellular matrix (stroma) components within such plaques (Snow et al., 1988, 1989; Narindrasorasak et al., 1991). Though differences in $A \beta$ fibril structure were observed in the presence and absence of $\mathrm{A} \beta$ plaques in the homogenates the results also proved different from in vitro $\mathrm{A} \beta$ fibril assemblies as seen with cryo-electron microscopy (Fandrich et al., 2011). It is still not clear which of these results reflect the in situ situation. The presence of unexpected twists in particular strands, or novel orientation of side chains of specific amino acid residues, as a result of the influence of the plaque or its stroma, may be very relevant in dictating the physical properties of fibrils in situ. They may also influence the kinetics of fibrils growth and generate specific conformations suitable for the binding of various ligands. These data raise the distinct possibility that in vivo components of tissue stroma have a role in the structure and potentially the anatomic site of the deposition process itself. This idea is consistent with the known presence of such components, e.g., serum amyloid P (SAP), apolipoprotein E (apoE), glycosaminoglycans (GAGs) such as heparan sulfate (HS), HS proteoglycan (HSPG), laminin and particular forms of collagen, in amyloid fibrils in situ (Lyon et al., 1991). Experimental studies examining fibrillogenesis of different amyloidogenic proteins on different tissue, or synthetic, matrices will probably become a ripe area for investigation and may succeed in enlightening us about the possible differences and similarities between amyloid-like fibrils in vitro and in situ amyloid fibrils. Initial explorations in this direction have already begun (Mazza et al., 2016).

Notwithstanding the substantial advances made understanding protein fibrillogenesis and fibril structure in vitro, progress regarding these processes in situ/in vivo has not proceeded apace. Currently, structural comparisons of ex vivo/in vitro fibrils with those observed in situ rest on relatively few studies. One similarity is their common Congo red and thioflavin $\mathrm{T}$ staining properties. There are but two infra-red studies of in situ amyloid, one examining procalcitonin and the other A $\beta$ amyloids in situ (O'Leary and Levin, 1985; Choo et al., 1996). There is but a single X-ray microprobe study of
$\mathrm{A} \beta$ in situ (Briki et al., 2011), a single cryo-fixation, freeze substitution and standard EM study of AA amyloid fibrils in situ (Inoue and Kisilevsky, 1999; Inoue et al., 2002), and one study of transthyretin amyloid fibrils extracted from the vitreous of the eye from a patient with a familial form of ATTR (Serpell et al., 1995). Whether the large body of information on in vitro/ex vivo fibrils and the limited structural information on in situ fibrils is sufficient to establish equivalence between the two sources of fibrils has yet to be settled.

The understanding of fibril composition and structure achieved from 1970 onwards rendered incorrect some preexisting concepts concerning the make-up of amyloid and its pathogenesis and required significant amendments. In 19701972 data emerged from several groups that at least one amyloid protein was not related to immunoglobulins (Benditt et al., 1971; Benditt and Eriksen, 1971, 1972; Ein et al., 1972; Hermodson et al., 1972). In 1970-1980, in addition to the AEF studies which questioned the role of immune mechanisms in AA amyloidogenesis, it became apparent that several different proteins could be responsible for amyloid deposits in vivo. During this period at least a dozen such proteins were identified and the number has now climbed to over 30 (Westermark et al., 2007). Each amyloid protein was shown to be associated with a distinct clinical disorder or pathologic process. The older idea that amyloid was always due to the same protein, regardless of tissue source, or clinical disorder, had to be discarded. Furthermore, many of the identified proteins had little, if anything, to do with immune function and the concept that an undefined immunological disturbance was at the basis of all amyloids has also been discarded. Moreover, not all of the identified amyloidogenic proteins appeared to require proteolysis for fibril assembly. There are multiple examples in which the full length unmodified protein is present in the natural fibrils which include SAA in ducks (Ericsson et al., 1987), a mutant variant of lysozyme (Pepys et al., 1993), and the natural variant of $\beta 2 \mathrm{M}$ (Valleix et al., 2012). Nor was it clear whether in some cases proteolytic cleavage was a pre- or post-fibrillogenic in vivo event. Since many of the tissue amyloid deposits had existed in vivo for months or years prior to their isolation and examination it remained possible that in vivo proteolytic attack occurring after deposition could generate a family of related peptides that could be purified from the isolated fibrils (Kisilevsky et al., 1994; Röcken et al., 2000; Enqvist et al., 2009). It is also possible that truncated species of a protein precursor, chemically identical to those found in natural fibrils, possesses strong amyloidogenic propensity (Esposito et al., 2000; Mangione et al., 2014), and can generate a fibril nucleus able to catalyze the aggregation of the less amyloidogenic full length protein.

Despite the wealth of basic knowledge on the biophysical basis of fibrillogenesis of native proteins in vitro the reasons why relatively few of the 20,000-25,000 proteins encoded by the genome are associated with amyloid deposition in humans and the mechanisms that drive the tissue selectivity of systemic amyloid deposition remains totally unexplained. Nevertheless, the acquired data have raised many questions related to amyloidogenesis, among which are: 
1. Is the cross beta-sheet structure of a fibrillar protein aggregate the lowest free energy state of that polypeptide, and is the main driving force for the conformational transition of the amyloidogenic protein in vivo the energy landscape in which it exists?

2. Are the in vitro fibrillogenic conditions ones that might be seen in vivo, and if so where do these occur anatomically?

3. Are the amyloid-like fibrils generated in vitro from a single protein really identical to, or only similar to, amyloid fibrils seen in vivo?

4. What role do co-precipitating components (e.g., SAP, GAGs, laminin, and type IV collagen of the extracellular matrix) known to be part of in vivo amyloid deposits play in amyloidogenesis (Kisilevsky, 2000)? Are they simply "associated" factors, or "critical" components, as suggested by inhibition of in vivo fibrillogenesis when one alters the availability of SAP (Pepys et al., 2002; Inoue et al., 2005; Bodin et al., 2010), or the state and/or quantity of HS (Kisilevsky et al., 2007).

5. Has our current focus primarily on proteins identified in amyloid-like fibrils inadvertently altered our definition of amyloid so that it has lost its previous clinical and pathological context? Has amyloid's original definition therefore become distorted to a "protein only" entity and problem? Such a perspective would distract/deflect us from understanding the role of additional components in amyloid structure, the more complex details of fibrillogenesis in vivo involving these additional components and potentially prevent us from considering broader therapeutic possibilities derived from an understanding of these complexities.

6. What roles do natural inhibitors of protein mis-folding, and stabilizers of protein conformation, (the "chaperones") play in amyloidogenesis in vivo?

7. How does a critical concentration of an amyloidogenic protein arise at anatomic sites remote from its site of biosynthesis?

8. How do amyloid deposits influence cell and tissue function and viability?

The basic concepts concerning protein folding and misfolding and their possible relationship to protein fibril assembly and amyloid formation are schematically presented in Figure 3, which is reproduced from Hartl and Hayer-Hartl (2009). In this scheme fibril formation is driven thermodynamically by the very low free energy of the fibrillar state. This deep free energy minimum is derived from the extensive formation of intermolecular hydrogen bonds, hydrophobic interactions and water exclusion from the inner core of the fibril. In the case of systemic amyloidoses the pathway of amyloidogenesis begins with native globular proteins that circulate freely in plasma, diffuse into the interstitial space but ordinarily possess a "local" free energy minimum that, in effect, prevents them from cascading further down the free energy scale unless they are perturbed to overcome this energy barrier. In vitro this barrier can be "softened" by altering the conditions in which the globular protein exits, such as increasing the temperature, reducing the $\mathrm{pH}$, introducing organic solvents, changing the sequence of the normal protein, or removing an associated

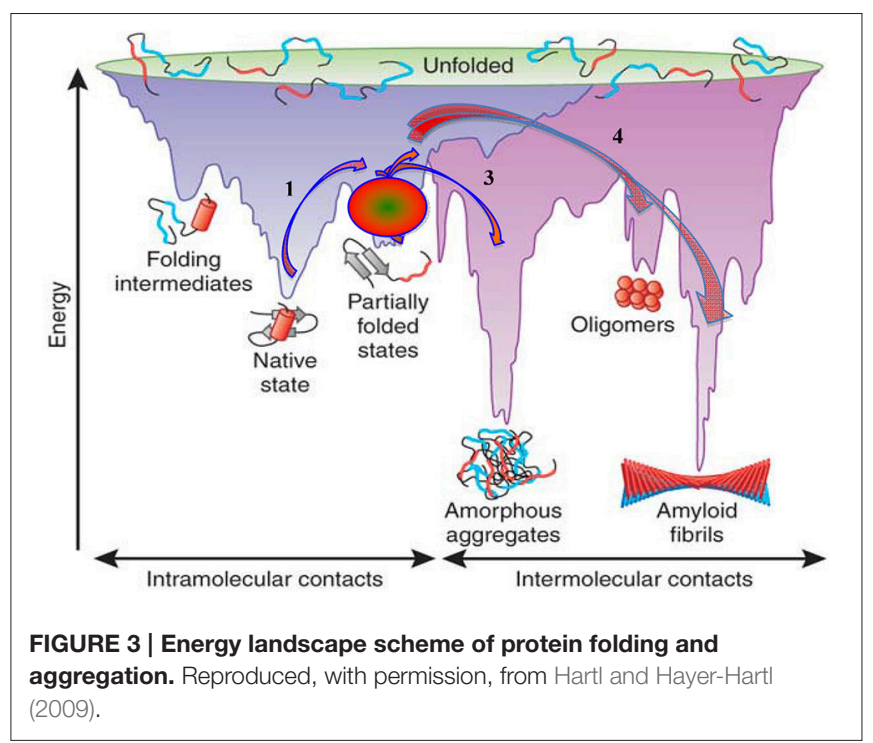

protein (Hatters et al., 2001; Rekas et al., 2004; Raman et al., 2005; Mangione et al., 2013). The sources providing sufficient energy to overcome the barrier in vivo are still largely undetermined and some proteins intrinsically amyloidogenic in in vitro experiments never overcome the barrier in vivo. Wild-type lysozyme is an example of a potentially amyloidogenic protein that never appears to enter the amyloid pathway. However, mutations may alter the minimum free energy of the native, and or, the intermediate states, effectively altering the free energy landscape making it possible (step 1, Figure 3) to proceed to a partially unfolded intermediate state. This intermediate and metastable state (step 2, Figure 3) appears to be a key step in any further transformation and a crucial entity in amyloid conversion. The intermediate state is most likely a population of heterogeneous conformers whose structural characterization is extremely difficult due to their rapid inter-conversions. The formation of an intermediate state in vivo has not yet been demonstrated but all in vitro evidence would indicate this also occurs in living systems.

A necessary property of any amyloidogenic globular protein appears to be its folding instability and almost all the methods of in vitro fibrillogenesis are based on conditions inducing a partial protein unfolding (Bellotti and Chiti, 2008). Several groups have investigated the fibrillogenesis of $\beta 2 \mathrm{M}$ which provides a good example of the evolution of concepts and methods related to the formation of amyloid-like fibrils in vitro (Stoppini and Bellotti, 2015). This progressed through the use of full length $\beta 2 \mathrm{M}$ and fibrillogenic seeding at low $\mathrm{pH}$, alterations in salt composition and concentration, use of truncated, or partially unfolded, forms of $\beta 2 \mathrm{M}$, introduction of GAGs at more neutral $\mathrm{pH}$, use of phosphate buffers and the use of a natural amyloidogenic variant (Naiki et al., 1997; Esposito et al., 2000; McParland et al., 2000; Chiti et al., 2001; Yamamoto et al., 2004a,b; Jahn et al., 2006; Relini et al., 2008; Eichner and Radford, 2011; Mangione et al., 2013).

Recent additional work on the first natural amyloidogenic variant of $\beta 2 \mathrm{M}$ has highlighted the role of shear forces generated 
by the flow of physiologic fluids and the exposure of this variant to hydrophobic surfaces (Valleix et al., 2012; Mangione et al., 2013). In particular in this variant the replacement of Asp76 by Asn destabilizes the folded state by $2.8 \mathrm{kcal} / \mathrm{mol}$. Nevertheless, in the cell, this variant is fully folded and functions properly through its stabilizing interaction with the Class I major histocompatibilty complex (Halabelian et al., 2014). A further property of this mutant form of $\beta 2 \mathrm{M}$ is that the single amino acid substitution drives the anatomic site of amyloid deposition. In fact the wildtype $\beta 2 \mathrm{M}$ is found primarily in large joints, bones and ligaments but the mutant form is deposited systemically.

\section{AMYLOID CELL AND TISSUE TARGETING IN VIVO}

In vivo deposition of amyloid may occur at, or close to, the biosynthetic site of its amyloidogenic precursor, or at a site remote from its site of synthesis. When at or near the site of biosynthesis, fibrillogenesis may occur within the cell or close to it extracellularly. Examples of the former are fibrils found within light-chain synthesizing plasma cells in multiple myeloma (Ishihara et al., 1991), phosphorylated tau fibrils found in neurons containing neurofibrillary tangles (Ruben et al., 1992; Snow et al., 1992), islet amyloid polypeptide (IAPP) in $\beta$-cells of the islets of Langerhans (de Koning et al., 1994b; Westermark et al., 2011) and amyloid-like fibrils seen in various species of yeast (Wickner et al., 2013). In each of these situations one can imagine an intracellular synthesized protein experiencing conditions (mutations, temperature, $\mathrm{pH}$, shear forces, protein concentration, or lack of proper chaperones) that alter the stability of the folded protein creating a micro-environment conducive to the generation of conformational intermediates, oligomer formation, and finally fibril formation as one sees in vitro.

In addition to being a protein that undergoes intracellular fibrillogenesis IAPP is also an example of extracellular amyloid deposited close to its site of synthesis. It is believed that $A \beta$ deposits in the central nervous system in Alzheimer's disease may represent another such example. These proteins are synthesized by local cells and after their export may find, in the immediate vicinity of this cell, conditions conducive to the generation of conformational intermediates, oligomer formation and then fibril deposition. However, IAPP is instructive for another reason. Its fibrils are found throughout the islets though not beyond its confines (de Koning et al., 1994a; Ma et al., 2000). If this protein, or its initial conformational intermediates, can diffuse beyond its cell of origin why does the amyloid end abruptly at the endocrine:exocrine interface and not also involve the immediately adjacent exocrine portions of the pancreas? What are the factors that restrict its deposition to the islets? The converse to this question is, what keeps some amyloidogenic proteins from being deposited as amyloid at/near their site of synthesis, but allows them to be deposited at other anatomic sites.

There are many forms of amyloid that fall into the class of "extracellular amyloid deposition remote from the site of synthesis of their protein precursors." In fact most clinically relevant forms of systemic amyloidosis belong in this category and include AA amyloid (a consequence of persistent acute inflammation), AL amyloid (a consequence of myeloma or Bcells dyscrasias), ATTR (transthyretin amyloid, many forms of which are a consequence of single amino acid substitutions), $\mathrm{A} \beta 2 \mathrm{M}$ (a consequence of long term hemodialysis), and several additional forms of amyloid such as those derived from fibrinogen (Asl et al., 1997) or apoA-I (Amarzguioui et al., 1998; Benson, 2001). This list is not complete. Among the many examples that can be discussed only AA, ATTR, and A $32 \mathrm{M}$ will be considered. Together they identify questions that need to be addressed if we are to understand, sift, and apply the information from studies of in vitro fibril formation to the in vivo setting.

The precursor to AA amyloid, SAA, is synthesized primarily in the liver and during an inflammatory reaction its plasma concentration may increase 1000 fold (McAdam et al., 1978). However, the deposition of SAA as AA amyloid occurs first in the spleen specifically the perifollicular zone within this organ as seen in mice and mink (Husby et al., 1975; Snow and Kisilevsky, 1985), and extensive follicular splenic deposition in humans (Buck and Koss, 1991; the "sago spleen" in Fontanus' original description of 1639). Why is this so? The follicle is the filtering zone within the spleen and one may argue that high plasma concentrations of SAA may lead to the formation of conformational intermediates and oligomers which are cleared by the spleen. If it is true, as shown in vitro, that conformational intermediates and oligomer formation is a common pathway from amyloid precursors to amyloid deposits then other amyloid precursors that exist in plasma should also follow this anatomic deposition pattern. This however is not the case. This follicular amyloid distribution is peculiar to AA amyloid. TTR, the precursor to ATTR, is also made primarily in the liver but its varying anatomic distribution as amyloid appears to be related to particular mutations. Wild-type TTR is seen mainly in the heart and in older individuals (Benson, 2012), the peripheral nervous system is the preference of one mutation (Benson and Uemichi, 1996), in another mutation deposition is almost exclusively in the heart (Buxbaum et al., 2010) and in yet another it is apparently in the leptomeninges (Benson, 1996; Nakagawa et al., 2008). The spleen is rarely, if ever, involved in ATTR regardless of the presence or absence of mutations. Similarly, fibrinogen and apoA-I are synthesized in the liver but are deposited in extra-hepatic sites. It appears therefore that if protein concentration, conformational instability, and oligomers play the role proposed in vitro it is more likely that the unstable forms and early aggregates are generated not close to the cell which synthesizes the precursor or in plasma but more likely in the micro-locale where these proteins are finally deposited. We know very little about potential micro-environmental factors (ligands, temperature, $\mathrm{pH}$, shear forces, protein concentration, or removal of chaperones), how they are generated, how they determine which organ is targeted by the different amyloidogenic proteins, and in particular why single amino acid substitutions in a specific amyloidogenic protein (e.g., TTR, apoA-I, or $\beta 2 \mathrm{M}$ ) changes the organs involved. 


\section{POTENTIAL FACTORS INFLUENCING TISSUE TARGETING}

The fact that single amino acid substitutions can change the tissue site of amyloid deposition suggests that some of the information determining this deposition resides in the structural and functional features of the amyloidogenic protein itself. But with what does the amyloidogenic protein interact and what is the effect of this environment? Though possible, it is unlikely that the ionic composition of interstitial fluid in tissue stroma varies significantly in different organs, or from one locale to another within the same organ. This suggests that attention should focus on larger molecular entities with which the amyloidogenic proteins may interact. Several possibilities come to mind.

1. Protein:protein interactions in the extracellular matrix are extremely varied and span a large range of affinities, from the low affinity of chaperones proteins to the high affinity of specific receptors. An example of the latter is the high affinity binding of SAA, the AA precursor, to laminin, a stromal protein. SAA has been shown to compete with entactin (a normal laminin ligand necessary for the building of basement membrane structures) for the laminin:entactin binding site (Ancsin and Kisilevsky, 1997, 1999). The interaction with the hydrophobic surfaces of fibrous proteins, constitutive components of the extracellular matrix, is also extremely important although the interaction is not specific for the amyloidogenic proteins. However, the effect of the interaction of hydrophobic surfaces and globular amyloidogenic proteins may be sufficiently specific that once such contact is made the amyloidogenic protein can unfold locally and its propensity to selfaggregate enhanced (Husby et al., 1994; Relini et al., 2006, 2008).

2. Protein:proteoglycan binding, particularly HSPG and its HS side chains. There is a substantial literature implicating HS in amyloidogenesis in vivo (Kisilevsky et al., 2007). Though HS has a common repeating disaccharide backbone that is the same from tissue to tissue and cell to cell, there is extensive variation in its pattern of sulfation and epimerization to account for different specificities between different tissues and for different specificities within the same tissue. Furthermore, these HS structural variations change with age and physiological states (Feyzi et al., 1998; Parish, 2006) and may explain why amyloids are more common later in life. Shear forces have been implicated in the clustering of HS (Zeng et al., 2013) and both of these factors have been shown to have an effect on protein fibrillization. Heparan sulfate has also been shown to play a role in dissociating SAA from HDL, its normal carrier in plasma (Noborn et al., 2012), and such a separation of SAA from HDL may alter SAA's conformational stability. Precisely how proteins bind/interact with HS, where their complimentary binding faces exist and how the specificities of protein binding are determined is a subject that cuts across many areas of research (Kisilevsky and Ancsin,
2010). Nevertheless, this binding has been used successfully as a therapeutic target in treating AA amyloidosis in animals and humans (Kisilevsky et al., 1995; Dember et al., 2007).

\section{CELL AND TISSUE INJURY CAUSED BY AMYLOID DEPOSITS}

At least two pathological mechanisms are apparently involved in amyloid causing cell and tissue injury. There may be others to be discovered in the future. Historically, the first mechanism is based on the gross and microscopic appearance of amyloid as seen at the organ and tissue levels (Kisilevsky, 2007). Organs infiltrated with large quantities of amyloid, regardless of type, become rigid and this rigidity may affect their function (e.g., the heart). At a histological level amyloid is deposited between blood vessels and parenchymal cells using the stromal architecture of the extracellular matrix (Kisilevsky, 2007). This is believed to impair the transfer of nutrients to, and of metabolic and functional products from, parenchymal cells affecting their physiological function. Histological observations also suggest that amyloid in situ surrounds parenchymal cells constricting the space about these cells (Kisilevsky, 2007). Such processes altering cell viability and function were suggested decades before the fibrillar nature of amyloid was understood. These older perspectives are no longer fashionable but there is little experimental evidence that rules them out. Additional proposals have arisen in the last 20 years based on cell/tissue culture data. Attempts to determine if large amyloid deposits, as seen histologically, had adverse properties vis a vis cell viability and function in culture proved disappointing. However, oligomeric units (small aggregates, not necessarily fibrillar) of amyloidogenic proteins did influence cell viability (Haass and Steiner, 2001; Glabe, 2006). It was therefore proposed that small fibrils/oligomers, rather than large amyloid aggregates formed in vivo were responsible for cell toxicity and altered cell function seen in vivo. This conclusion needs to be tempered, and the dismissal of the in vivo cell and tissue effects of large amyloid deposits is premature because the anatomic relationship of large aggregates to cells in culture is not analogous to amyloid seen in the extracellular matrix between cells, and between cells and capillaries in vivo. Nevertheless, there is ample evidence that monomers and oligomers do have an effect on cell viability in culture and in vivo. An interesting example of the former is impaired cardiac function in $\mathrm{AL}$ amyloid and its positive correlation with the plasma level of free amyloidogenic light chains rather than the quantity of amyloid deposited in the heart (Palladini et al., 2006). However, in these patients to fully express their toxicity the soluble prefibrillar species requires the presence of amyloid deposits in the tissues.

Additional studies have revealed that amyloidogenic monomers can form beta barrels and they, as well as oligomers, can insert themselves into cell membranes (plasma membranes and intra-cellularly) altering cell permeability, or creating membrane pores and impairing mitochondrial and endoplasmic reticulum function with devastating consequences (Haass and 
Steiner, 2001; Glabe, 2006). Monomers, oligomers as well as large amyloid deposits may be operative in vivo but only the first two can be demonstrated in culture. Furthermore, in vivo their effects may be additive or synergistic and their adverse effects fully expressed when both fibrils and precursor are abundantly present. Additionally, amyloid fibrils in the extracellular matrix may enhance the mis-folding and aggregation of adjacent corresponding precursor globular proteins (Bellotti and Chiti, 2008). To study such questions it may be possible to generate scaffolds that mimic the extracellular matrix and use them as tools to study the interplay between matrix, amyloid precursors, and amyloid fibrils.

\section{SUMMARY}

A consideration of the general determinants that govern which tissues are targeted by which amyloidogenic proteins is an aspect that at present is not being, or cannot be, addressed/assessed in vitro. The generation of critical protein concentrations and the behavior of conformational intermediates and oligomers in vitro do not necessarily indicate how and where these are formed in vivo. They are not likely to be formed adjacent to the cells synthesizing the protein nor in plasma as, being particulate, they would likely be cleared by the reticulo-endothelial system and the different amyloids would have very similar tissue distributions. This suggests that conformational intermediates and oligomers are generated close to the site of amyloid deposition, and are subject to the same factors that determine the specific tissue distribution of amyloids.

\section{REFERENCES}

Amarzguioui, M., Mucchiano, G., Häggqvist, B., Westermark, P., Kavlie, A., Sletten, K., et al. (1998). Extensive intimal apolipoprotein A1-derived amyloid deposits in a patient with an apolipoprotein A1 mutation. Biochem. Biophys. Res. Commun. 242, 534-539. doi: 10.1006/bbrc.1997.8005

Ancsin, J. B., and Kisilevsky, R. (1997). Characterization of high affinity binding between laminin and the acute-phase protein, serum amyloid A. J. Biol. Chem. 272, 406-413. doi: 10.1074/jbc.272.1.406

Ancsin, J. B., and Kisilevsky, R. (1999). Laminin interactions with the apoproteins of acute-phase HDL: preliminary mapping of the laminin binding site on serum amyloid A. Amyloid 6, 37-47. doi: 10.3109/135061299089 93286

Asl, L. H., Liepnieks, J. J., Uemichi, T., Rebibou, J. M., Justrabo, E., Grateau, G., et al. (1997). Renal amyloidosis with a frame shift mutation in fibrinogen A $\alpha$-chain gene producing a novel amyloid protein. Blood 90, 4799-4805.

Axelrad, M. A., and Kisilevsky, R. (1980). "Biological characterizations of amyloid enhancing factor," in Amyloid and Amyloidosis, eds G. G. Glenner, P. P. Costa, and F. de Freitas (Amsterdam: Excerpta Medica), 527-533.

Axelrad, M. A., Kisilevsky, R., and Beswetherick, S. (1975). Acceleration of amyloidosis by syngeneic spleen cells from normal donors. Am. J. Pathol. 78, 277-284.

Axelrad, M. A., Kisilevsky, R., Willmer, J., Chen, S. J., and Skinner, M. (1982). Further characterization of amyloid enhancing factor. Lab. Invest. 47, 139-146.

Barbet-Massin, E., Ricagno, S., Lewandowski, J. R., Giorgetti, S., Bellotti, V., Bolognesi, M., et al. (2010). Fibrillar vs crystalline full-length beta-2microglobulin studied by high-resolution solid-state NMR spectroscopy. J. Am. Chem. Soc. 132, 5556-5557. doi: 10.1021/ja1002839

\section{AUTHOR CONTRIBUTIONS}

RK and VB provided the majority of the thought concerning the concepts considered and did the majority of the writing. SR assisted in the organization of the paper tracking the references and organizing the bibliography.

\section{FUNDING}

Please note that the manuscript is not a typical review, but a perspective and review of the concepts that have driven amyloid research over the last 350 years. RK and VB have been conducting basic and applied research in this area for a combined total of more than 75 years and have been funded by dozens of agencies during this time. We sincerely thank all these agencies, which are each listed in the respective publications which they supported, and, for their very generous support over the period 1970-present. We could not have achieved our contributions and nor developed our perspectives in this research area in the absence of such wide support.

\section{ACKNOWLEDGMENTS}

Some of the material described under "Cell and Tissue Injury Caused by Amyloid Deposits" was presented at the XIIIth International Symposium on Amyloidosis held in Groningen, The Netherlands and published in the Proceedings of that meeting (Kisilevsky, 2013).

Bellotti, V., and Chiti, F. (2008). Amyloidogenesis in its biological environment: challenging a fundamental issue in protein misfolding diseases. Curr. Opin. Struct. Biol. 18, 771-779. doi: 10.1016/j.sbi.2008.10.001

Benditt, E. P., and Eriksen, N. (1971). Chemical classes of amyloid substance. Am. J. Pathol. 65, 231-251.

Benditt, E. P., and Eriksen, N. (1972). Chemical similarity among amyloid substances associated with long standing inflammation. Lab. Invest. 26, 615-625.

Benditt, E. P., Eriksen, N., Hermodson, M. A., and Ericsson, L. H. (1971). The major proteins of human and monkey amyloid substance: common properties including unusual N-terminal amino acid sequences. FEBS Lett. 19, 169-173. doi: 10.1016/0014-5793(71)80506-9

Bennhold, H. (1922). Specific staining of amyloid by Congo red. Munch. Med. Wschr. 69, 1537-1538.

Benson, M. D. (1996). Leptomeningeal amyloid and variant transthyretins. Am. J. Pathol. 148, 351-354.

Benson, M. D. (2001). The apolipoprotein amyloidoses. Amyloid 8(Suppl. 2), 28.

Benson, M. D. (2012). Pathogenesis of transthyretin amyloidosis. Amyloid 19(Suppl. 1), 14-15. doi: 10.3109/13506129.2012.668501

Benson, M. D., and Uemichi, T. (1996). Transthyretin amyloidosis. Amyloid 3, 44-56. doi: 10.3109/13506129609014354

Bodin, K., Ellmerich, S., Kahan, M. C., Tennent, G. A., Loesch, A., Gilbertson, J. A., et al. (2010). Antibodies to human serum amyloid P component eliminate visceral amyloid deposits. Nature 468, 93-97. doi: 10.1038/nature09494

Briki, F., Vérine, J., Doucet, J., Bénas, P., Fayard, B., Delpech, M., et al. (2011). Synchrotron $\mathrm{x}$-ray microdiffraction reveals intrinsic structural features of amyloid deposits in situ. Biophys. J. 101, 486-493. doi: 10.1016/j.bpj.2011.05.055 
Buck, F. S., and Koss, M. N. (1991). Hepatic amyloidosis - morphologic differences between systemic AL and AA types. Hum. Pathol. 22, 904-907. doi: 10.1016/0046-8177(91)90180-W

Buell, A. K., Dobson, C. M., and Knowles, T. P. (2014). The physical chemistry of the amyloid phenomenon: thermodynamics and kinetics of filamentous protein aggregation. Essays Biochem. 56, 11-39. doi: 10.1042/bse0560011

Buxbaum, J., Alexander, A., Koziol, J., Tagoe, C., Fox, E., and Kitzman, D. (2010). Significance of the amyloidogenic transthyretin Val 122 Ile allele in African Americans in the Arteriosclerosis Risk in Communities (ARIC) and Cardiovascular Health (CHS) Studies. Am. Heart J. 159, 864-870. doi: 10.1016/j.ahj.2010.02.006

Chiti, F., Bucciantini, M., Capanni, C., Taddei, N., Dobson, C. M., and Stefani, M. (2001). Solution conditions can promote formation of either amyloid protofilaments or mature fibrils from the HypF N-terminal domain. Protein Sci. 10, 2541-2547. doi: 10.1110/ps.ps.10201

Choo, L. P., Wetzel, D. L., Halliday, W. C., Jackson, M., Levine, S. M., and Mantsch, H. H. (1996). In situ characterization of b-amyloid in Alzheimer's diseased tissue by synchrotron Fourier transform infrared microspectroscopy. Biophys. J. 71, 1672-1679. doi: 10.1016/S0006-3495(96)79411-0

Cohen, A. S., and Calkins, E. (1959). Electron microscopic observations on fibrous component in amyloid of diverse origins. Nature 183, 1202-1203. doi: 10.1038/1831202a0

Cohen, A. S., and Calkins, E. (1964). The isolation of amyloid fibrils and a study of the effect of collagenase and hyaluronidase. J. Cell Biol. 21, 481-486. doi: 10.1083/jcb.21.3.481

Comellas, G., Lemkau, L. R., Nieuwkoop, A. J., Klooppere, K. D., Ladror, U. S., Ebisu, R., et al. (2011). Structured regions of a-synuclein fibrils include the early-onset Parkinson's disease mutation sites. J. Mol. Biol. 411, 881-895. doi: 10.1016/j.jmb.2011.06.026

Debelouchina, G. T., Bayro, M. J., Fitzpatrick, A. W., Ladizhansky, V., Colvin, M. T., Caporini, M. A., et al. (2013). Higher order amyloid fibril structure by MAS NMR and DNP spectroscopy. J. Am. Chem. Soc. 135, 19237-19247. doi: 10.1021/ja409050a

Debelouchina, G. T., Platt, G. W., Bayro, M. J., Radford, S. E., and Griffin, R. G. (2010). Intermolecular alignment in $\beta 2$-microglobulin amyloid fibrils. J. Am. Chem. Soc. 132, 17077-17079. doi: 10.1021/ja107987f

de Koning, E. J., Höppener, J. W., Verbeek, J. S., Oosterwijk, C., van Hulst, K. L., Baker, C. A., et al. (1994a). Human islet amyloid polypeptide accumulates at similar sites in islets of transgenic mice and humans. Diabetes 43, 640-644. doi: 10.2337/diab.43.5.640

de Koning, E. J., Morris, E. R., Hofhuis, F. M., Posthuma, G., Höppener, J. W., Morris, J. F., et al. (1994b). Intra- and extracellular amyloid fibrils are formed in cultured pancreatic islets of transgenic mice expressing human islet amyloid polypeptide. Proc. Natl. Acad. Sci. U.S.A. 91, 8467-8471. doi: 10.1073/pnas.91.18.8467

Dember, L. M., Hawkins, P. N., Hazenberg, B. P. C., Gorevic, P. D., Merlini, G., Butrimiene, I., et al. (2007). Eprodisate for the treatment of renal disease in AA amyloidosis. N. Engl. J. Med. 356, 2349-2360. doi: 10.1056/NEJMoa065644

Eichner, T., and Radford, S. E. (2011). Understanding the complex mechanisms of beta(2) -microglobulin amyloid assembly. FEBS J. 278, 3868-3883. doi: 10.1111/j.1742-4658.2011.08186.x

Ein, D., Kimura, S., Terry, W. D., Magnotta, J., and Glenner, G. G. (1972). Amino acid sequence of an amyloid fibril protein of unknown origin. J. Biol. Chem. $247,5653-5655$

Enqvist, S., Sletten, K., and Westermark, P. (2009). Fibril protein fragmentation pattern in systemic AL-amyloidosis. J. Pathol. 219, 473-480. doi: 10.1002/path. 2607

Ericsson, L. H., Eriksen, N., Walsh, K. A., and Benditt, E. P. (1987). Primary structure of duck amyloid protein A: the form deposited in tissues may be identical to its serum precursor. FEBS Lett. 218, 11-16. doi: 10.1016/00145793(87)81008-6

Esposito, G., Michelutti, R., Verdone, G., Viglino, P., Hernandez, H., Robinson, C., et al. (2000). Removal of the N-terminal hexapeptide from human b2microglobulin facilitates protein aggregation and fibril formation. Protein Sci. 9, 831-845. doi: $10.1110 /$ ps.9.5.831

Fandrich, M., Schmidt, M., and Grigorieff, N. (2011). Recent progress in understanding Alzheimer's $\beta$-amyloid structures. Trends Biochem. Sci. 36, 338-345. doi: $10.1016 /$ j.tibs.2011.02.002
Feyzi, E., Saldeen, T., Larsson, E., Lindahl, U., and Salmivirta, M. (1998). Agedependent modulation of heparan sulfate structure and function. J. Biol. Chem. 273, 13395-13398. doi: 10.1074/jbc.273.22.13395

Franklin, E. C., and Pras, M. (1969). Immunologic studies of water-soluble human amyloid fibrils. Comparative studies of eight amyloid preparations. J. Exp. Med. 130, 797-808. doi: 10.1084/jem.130.4.797

Friedrich, N., and Kekule, A. (1859). Zur amyloidfrage. Virchows Arch. Pathol. Anat. Physiol. 16, 50-65. doi: 10.1007/BF01945246

Glabe, C. G. (2006). Common mechanisms of amyloid oligomer pathogenesis in degenerative disease. Neurobiol. Aging 27, 570-575. doi: 10.1016/j.neurobiolaging.2005.04.017

Glenner, G. G. (1972). The discovery of the immunoglobulin origin of amyloid fibrils and its pathogenetic significance. Acta Pathol. Microbiol. Scand. 233, 114-121.

Glenner, G. G., Ein, D., Eanes, E. D., Bladen, H. A., Terry, W., and Page, D. L. (1971a). Creation of "amyloid" fibrils from Bence Jones proteins in vitro. Science 174, 712-714. doi: 10.1126/science.174.4010.712

Glenner, G. G., Harbaugh, J., Ohms, J. I., Harada, M., and Cuatrecasas, P. (1970). An amyloid protein: the amino-terminal variable fragment of an immunoglobulin light chain. Biochem. Biophys. Res. Commun. 41, 1287-1289. doi: 10.1016/0006-291X(70)90227-5

Glenner, G. G., Page, D., Isersky, C., Harada, M., Cuatrecasas, P., Eanes, E., et al. (1971b). Murine amyloid fibril protein: isolation, purification and characterization. J. Histochem. Cytochem. 19, 16-28. doi: 10.1177/19.1.16

Glenner, G. G., Terry, W., Harada, M., Isersky, C., and Page, D. (1971c). Amyloid fibril proteins: proof of homology with immunoglobulin light chains by sequence analysis. Science 172, 1150-1151. doi: 10.1126/science.172.3988.1150

Haass, C., and Steiner, H. (2001). Protofibrils, the unifying toxic molecule of neurodegenerative disorders? Nat. Neurosci. 4, 859-860. doi: 10.1038/nn 0901-859

Halabelian, L., Ricagno, S., Giorgetti, S., Santambrogio, C., Barbiroli, A., Pellegrino, S., et al. (2014). Class I major histocompatibility complex, the trojan horse for secretion of amyloidogenic $\beta 2$-microglobulin. J. Biol. Chem. 289, 3318-3327. doi: $10.1074 /$ jbc.M113.524157

Harada, M., Isersky, C., Cuatrecasas, P., Page, D., Bladen, H. A., Eanes, D., et al. (1971). Human amyloid protein: chemical variability and homogeneity. J. Histochem. Cytochem. 19, 1-15. doi: 10.1177/19.1.1

Hartl, F. U., and Hayer-Hartl, M. (2009). Converging concepts of protein folding in vitro and in vivo. Nat. Struct. Mol. Biol. 16, 574-581. doi: 10.1038/nsmb.1591

Hatters, D. M., Lindner, R. A., Carver, J. A., and Howlett, G. J. (2001). The molecular chaperone, a-crystallin, inhibits amyloid formation by apolipoprotein C-II. J. Biol. Chem. 276, 33755-33761. doi: 10.1074/jbc.M105285200

Hellmus, J. J., Surewicz, K., Apostol, M. I., Surewicz, W. K., and Jaroniec, C. P. (2011). Intermolecular alignment in Y145Stop human prion protein amyloid fibrils probed by solid-state NMR spectroscopy. J. Am. Chem. Soc. 133, 13934-13937. doi: 10.1021/ja206469q

Hermodson, M. A., Kuhn, R. W., Walsh, K. A., Neurath, H., Eriksen, N., and Benditt, E. P. (1972). Amino acid sequence of monkey amyloid protein A. Biochemistry 11, 2934-2938. doi: 10.1021/bi00766a002

Howie, A. J., and Brewer, D. B. (2009). Optical properties of amyloid stained by Congo red: history and mechanisms. Micron 40, 285-301. doi: 10.1016/j.micron.2008.10.002

Howie, A. J., Brewer, D. B., Howell, D., and Jones, A. P. (2008). Physical basis of colors seen in Congo red-stained amyloid in polarized light. Lab. Invest. 88, 232-242. doi: 10.1038/labinvest.3700714

Husby, G., Natvig, J. B., Sletten, K., Nordstoga, K., and Anders, R. F. (1975). An experimental model in mink for studying the relation between amyloid fibril protein AA and the related serum protein, SAA. Scand. J. Immunol. 4, 811-816. doi: 10.1111/j.1365-3083.1975.tb03721.x

Husby, G., Stenstad, T., Magnus, J. H., Sletten, K., Nordvåg, B. Y., and Marhaug, G. (1994). Interaction between circulating amyloid fibril protein precursors and extracellular tissue matrix components in the pathogenesis of sstemic ayloidosis. Clin. Immunol. Immunopathol. 70, 2-9. doi: 10.1006/clin.1994. 1002

Inoue, S., Kawano, H., Ishihara, T., Maeda, S., and Ohno, S. (2005). Formation of experimental murine AA amyloid fibrils in SAP-deficient mice: high resolution ultrastructural study. Amyloid 12, 157-163. doi: 10.1080/13506120500232010 
Inoue, S., and Kisilevsky, R. (1999). In situ electron microscopy of amyloid deposits in tissues. Methods Enzymol. 309, 496-509. doi: 10.1016/S0076-6879(99) 09034-5

Inoue, S., Kuroiwa, M., and Kisilevsky, R. (2002). AA protein in experimental murine AA amyloid fibrils: a high resolution ultrastructural and immunohistochemical study comparing aldehyde-fixed and cryofixed tissues. Amyloid 9, 115-125.

Ishihara, T., Takahashi, M., Koga, M., Yokota, T., Yamashita, Y., and Uchino, F. (1991). Amyloid fibril formation in the rough endoplasmic reticulum of plasma cells from a patient with localized A $\lambda$ Amyloidosis. Lab. Invest. 64, 265-271. doi: 10.1007/978-94-011-3284-8_132

Jahn, T. R., Parker, M. J., Homans, S. W., and Radford, S. E. (2006). Amyloid formation under physiological conditions proceeds via a native-like folding intermediate. Nat. Struct. Mol. Biol. 13, 195-201. doi: 10.1038/nsmb1058

Kisilevsky, R. (2000). Review: amyloidogenesis-unquestioned answers and unanswered questions. J. Struct. Biol. 130, 99-108. doi: 10.1006/jsbi.2000.4222

Kisilevsky, R. (2007). "The amyloidoses," in Pathology: A Clinicopathological Approach, eds E. Rubin and D Strayer (Philadelphia, PA: Lipincott, Williams and Wilkins), 989-998.

Kisilevsky, R. (2013). "Cell toxicity and amyloid tissue targeting," in Proceedings of the XIIIth International Symposium on Amyloidosis "From Misfolded Proteins to Well-Designed Treatment," eds B. P. C Hazenberg and J. Bijzet (Groningen: GUARD), 69-71.

Kisilevsky, R., and Ancsin, J., B. (2010). "Why study the role of heparan sulfate in in vivo amyloidogenesis," in Protein Misfolding Diseases:Current and Emerging Principles and Therapies, eds M. Ramirez-Alvarado, J. W. Kelly, and C. M. Dobson (Hoboken, NJ: John Wiley and Sons, Inc.), 559-569.

Kisilevsky, R., Ancsin, J. B., Szarek, W. A., and Petanceska, S. (2007). Heparan sulfate as a therapeutic target in amyloidogenesis: prospects and possible complications. Amyloid 14, 21-32. doi: 10.1080/13506120601116419

Kisilevsky, R., and Boudreau, L. (1983). The kinetics of amyloid deposition: I. The effect of amyloid enhancing factor and splenectomy. Lab. Invest. 48, 53-59.

Kisilevsky, R., Lemieux, L. J., Fraser, P. E., Kong, X. Q., Hultin, P. G., and Szarek, W. A. (1995). Arresting amyloidosis in vivo using small-molecule anionic sulphonates or sulphates: implications for Alzheimer's disease. Nat. Med. 1, 143-148. doi: 10.1038/nm0295-143

Kisilevsky, R., Narindrasorasak, S., Tape, C., Tan, R., and Boudreau, L. (1994). During AA amyloidogenesis is proteolytic attack on serum amyloid A a preor post-fibrillogenic event? Amyloid 1, 174-183. doi: 10.3109/135061294091 48449

Kyle, R. A. (2001). Amyloidosis: a convoluted story. Br. J. Haematol. 114, 529-538. doi: 10.1046/j.1365-2141.2001.02999.x

Lu, J. X., Qiang, W., Yau, W. M., Schwieters, C. D., Meredith, S. C., and Tycko, R. (2013). Molecular structure of $\beta$-amyloid fibrils in Alzheimer's disease brain tissue. Cell 154, 1257-1268. doi: 10.1016/j.cell.2013.08.035

Lyon, A. W., Narindrasorasak, S., Young, I. D., Anastassiades, T., Couchman, J. R., McCarthy, K., et al. (1991). Co-deposition of basement membrane components during the induction of murine splenic AA amyloid. Lab. Invest. 64, 785-790.

Ma, Z., Westermark, P., and Westermark, G. T. (2000). Amyloid in human islets of Langerhans: immunologic evidence that islet amyloid polypeptide is modified in amyloidogenesis. Pancreas 21, 212-218. doi: 10.1097/00006676-20000800000015

Mangione, P. P., Esposito, G., Relini, A., Raimondi, S., Porcari, R., Giorgetti, S., et al. (2013). Structure, folding dynamics, and amyloidogenesis of D76N $\beta 2$ microglobulin: roles of shear flow, hydrophobic surfaces, and a-crystallin. J. Biol. Chem. 288, 30917-30930. doi: 10.1074/jbc.M113.498857

Mangione, P. P., Porcari, R., Gillmore, J. D., Pucci, P., Monti, M., Porcari, M., et al. (2014). Proteolytic cleavage of Ser52Pro variant transthyretin triggers its amyloid fibrillogenesis. Proc. Natl. Acad. Sci. U.S.A. 111, 1539-1544. doi: 10.1073/pnas.1317488111

Mazza, G., Simons, J. P., Al Shawi, R., Ellmerich, S., Urbani, L., Giorgetti, S., et al. (2016). Amyloid persistence in decellularized liver: biochemical and histopathological characterization. Amyloid 23, 1-7. doi: 10.3109/13506129.2015.1110518

McAdam, K. P., Elin, R. J., Sipe, J. D., and Wolff, S. M. (1978). Changes in human serum amyloid-A and C-reactive protein after etiocholanolone-induced inflammation. J. Clin. Invest. 61, 390-394. doi: 10.1172/JCI108949
McParland, V. J., Kad, N. M., Kalverda, A. P., Brown, A., Kirwin-Jones, P., Hunter, M. G., et al. (2000). Partially unfolded states of $\beta_{2}$-microglobulin and amyloid formation in vitro. Biochemistry 39, 8735-8746. doi: 10.1021/bi000276j

Naiki, H., Hashimoto, N., Suzuki, S., Kimura, H., Nakakuki, K., and Gejyo, F. (1997). Establishment of a kinetic model of dialysis-related amyloid fibril extension in vitro. Amyloid 4, 223-232. doi: 10.3109/13506129709003833

Nakagawa, K., Sheikh, S. I., Snuderl, M., Frosch, M. P., and Greenberg, S. M. (2008). A new Thr49Pro transthyretin gene mutation associated with leptomeningeal amyloidosis. J. Neurol. Sci. 272, 186-190. doi: 10.1016/j.jns.2008.05.014

Narindrasorasak, S., Young, I., Aubin, S., Ludwin, S. K., and Kisilevsky, R. (1991). "Basement membrane heparan sulphate proteoglycan is part of isolated Alzheimer's amyloid plaques," in Alzheimer's disease: Basic mechanisms, Diagnosis, and Therapeutic Stratagies, eds. K. Iqbal, D. R. C. McLachlan, B. Winblad, and H. M. Wisniewski (Sussex: John Wiley and Sons Ltd.), 289-296.

Noborn, F., Ancsin, J. B., Ubhayasekera, W., Kisilevsky, R., and Li, J. P. (2012). Heparan sulfate dissociates serum amyloid A (SAA) from acute-phase high-density lipoprotein, promoting SAA aggregation. J. Biol. Chem. 287, 25669-25677. doi: 10.1074/jbc.M112.363895

O'Leary, T. J., and Levin, I. W. (1985). Secondary structure of endocrine amyloid: infrared spectroscopy of medullary carcinoma of the thyroid. Lab. Invest. 53, 240-242.

Palladini, G., Lavatelli, F., Russo, P., Perlini, S., Perfetti, V., Bosoni, T., et al. (2006). Circulating amyloidogenic free light chains and serum $\mathrm{N}$-terminal natriuretic peptide type B decrease simultaneously in association with improvement of survival in AL. Blood 107, 3854-3858. doi: 10.1182/blood-2005-11-4385

Parish, C. R. (2006). The role of heparan sulphate in inflammation. Nat. Rev. Immunol. 6, 633-643. doi: 10.1038/nri1918

Pepys, M. B., Hawkins, P. N., Booth, D. R., Vigushin, D. M., Tennent, G. A., Soutar, A. K., et al. (1993). Human lysozyme gene mutations cause hereditary systemic amyloidosis. Nature 362, 553-557. doi: 10.1038/362553a0

Pepys, M. B., Herbert, J., Hutchinson, W. L., Tennent, G. A., Lachmann, H., J., Gallimore, J. R., et al. (2002). Targeted pharmacological depletion of serum amyloid P component for treatment of human amyloidosis. Nature 417, 254-259. doi: 10.1038/417254a

Petkova, A. T., Yau, W. M., and Tycko, R. (2006). Experimental constraints on quaternary structure in Alzheimer's beta-amyloid fibrils. Biochemistry 45, 498-512. doi: 10.1021/bi051952q

Pras, M., Schubert, M., Zucker-Franklin, D., Rimon, A., and Franklin, E. C. (1968). The characterization of soluble amyloid prepared in water. J. Clin. Invest. 47, 924-933. doi: 10.1172/JCI105784

Raman, B., Ban, T., Sakai, M., Pasta, S. Y., Ramakrishna, T., Naiki, H., et al. (2005). $\alpha \mathrm{B}$-crystallin, a small heat-shock protein, prevents the amyloid fibril growth of an amyloid $\beta$-peptide and beta 2 -microglobulin. Biochem. J. 392, 573-581. doi: 10.1042/BJ20050339

Rekas, A., Adda, C. G., Andrew-Aquilina, J., Barnham, K. J., Sunde, M., Galatis, D., et al. (2004). Interaction of the molecular chaperone $\alpha \mathrm{B}$-crystallin with asynuclein: effects on amyloid fibril formation and chaperone activity. J. Mol. Biol. 340, 1167-1183. doi: 10.1016/j.jmb.2004.05.054

Relini, A., Canale, C., De Stefano, S., Rolandi, R., Giorgetti, S., Stoppini, M., et al. (2006). Collagen plays an active role in the aggregation of beta2-microglobulin under physiopathological conditions of dialysis-related amyloidosis. J. Biol. Chem. 281, 16521-16529. doi: 10.1074/jbc.M513827200

Relini, A., De Stefano, S., Torrassa, S., Cavalleri, O., Rolandi, R., Gliozzi, A., et al. (2008). Heparin strongly enhances the formation of beta 2-microglobulin amyloid fibrils in the presence of type I collagen. J. Biol. Chem. 283, 4912-4920. doi: $10.1074 / \mathrm{jbc} . M 702712200$

Röcken, C., Hegenbarth, V., Schmitz, M., Stix, B., Schade, G., Mohnert, A., et al. (2000). Plasmacytoma of the tonsil with AL amyloidosis: evidence of postfibrillogenic proteolysis of the fibril protein. Virchows Archiv. 436, 336-344. doi: $10.1007 / \mathrm{s} 004280050456$

Ruben, G. C., Iqbal, K., Wisniewski, H. M., Johnson, J. E., and GrundkeIqbal, I. (1992). Alzheimer neurofibrillary tangles contain $2.1 \mathrm{~nm}$ filaments structurally identical to the microtubule-associated protein-tau: a highresolution transmission electron microscope study of tangles and senile plaque core amyloid. Brain Res. 590, 164-179. doi: 10.1016/0006-8993(92)91092-S

Saraiva, M. J. (2001). Transthyretin amyloidosis - Current trends and perspectives. Amyloid 8(Suppl. 2), 103. 
Serpell, L. C., Sunde, M., Fraser, P. E., Luther, P. K., Morris, E. P., Sangren, O., et al. (1995). Examination of the structure of the transthyretin amyloid fibril by image reconstruction from electron micrographs. J. Mol. Biol. 254, 113-118. doi: 10.1006/jmbi.1995.0604

Sipe, J. D., and Cohen, A. S. (2000). Review: history of the amyloid fibril. J. Struct. Biol. 130, 88-98. doi: 10.1006/jsbi.2000.4221

Snow, A. D., and Kisilevsky, R. (1985). Temporal relationship between glycosaminoglycan accumulation and amyloid deposition during experimental amyloidosis: a histochemical study. Lab. Invest. 53, 37-44.

Snow, A. D., Lara, S., Nochlin, D., and Wight, T. N. (1989). Cationic dyes reveal proteoglycans structurally integrated within the characteristic lesions of Alzheimers disease. Acta Neuropathol. 78, 113-123. doi: 10.1007/BF006 88198

Snow, A. D., Mar, H., Nochlin, D., Kimata, K., Kato, M., Suzuki, S., et al. (1988). The presence of heparan sulfate proteoglycans in the neuritic plaques and congophilic angiopathy in Alzheimer's disease. Am. J. Pathol. 133, $456-463$.

Snow, A. D., Mar, H., Nochlin, D., Kresse, H., and Wight, T. N. (1992). Peripheral distribution of dermatan sulfate proteoglycans (decorin) in amyloid-containing plaques and their presence in neurofibrillary tangles of Alzheimer's disease. J. Histochem. Cytochem. 40, 105-113. doi: 10.1177/40.1. 1370306

Stoppini, M., and Bellotti, V. (2015). Systemic amyloidosis: lessons from beta2microglobulin. J. Biol. Chem. 290, 9951-9958. doi: 10.1074/jbc.R115.639799

Valleix, S., Gillmore, J. D., Bridoux, F., Mangione, P. P., Dogan, A., Nedelec, B., et al. (2012). Hereditary systemic amyloidosis due to Asp76Asn variant beta2-microglobulin. N. Engl. J. Med. 366, 2276-2283. doi: 10.1056/NEJMoa 1201356

Virchow, R. (1854). Zur cellulosefrage. Virchows Arch. Pathol. Anat. Physiol. 6, 416-426. doi: 10.1007/BF02116546

Wasmer, C., Lange, A., Van Melkebeke, H., Siemer, A. B., Riek, R., and Meier, B. H. (2008). Amyloid fibrils of the HET-s(218-289) prion form a beta solenoid with a triangular hydrophobic core. Science 319, 1523-1526. doi: $10.1126 /$ science. 1151839

Westermark, P. (2005). "Amyloidosis and amyloid proteins: brief history and definitions," in Amyloid Proteins. The Beta Sheet Conformation and Disease, ed J. D. Sipe (Weiheim: Wiley and Co.), 1-27.
Westermark, P., Andersson, A., and Westermark, G., T. (2011). Islet amyloid polypeptide, islet amyloid, and diabetes mellitus. Physiol. Rev. 91, 795-826. doi: 10.1152/physrev.00042.2009

Westermark, P., Benson, M. D., Buxbaum, J. N., Cohen, A. S., Frangione, B., Ikeda, S., et al. (2007). A primer of amyloid nomenclature. Amyloid 14, 179-183. doi: $10.1080 / 13506120701460923$

Wickner, R. B., Edskes, H. K., Bateman, D. A., Kelly, A. C., Gorkovskiy, A., Dayani, Y., et al. (2013). Amyloids and yeast prion biology. Biochemistry 52, 1514-1527. doi: 10.1021/bi301686a

Yamamoto, S., Hasegawa, K., Yamaguchi, I., Tsutsumi, S., Kardos, J., Goto, Y., et al. (2004a). Low concentrations of sodium dodecyl sulfate induce the extension of beta(2)-microglobulin-related amyloid fibrils at a neutral pH. Biochemistry 43, 11075-11082. doi: 10.1021/bi049262u

Yamamoto, S., Yamaguchi, I., Hasegawa, K., Tsutsumi, S., Goto, Y., Gejyo, F., et al. (2004b). Glycosaminoglycans enhance the trifluoroethanol-induced extension of beta 2-microglobulin-related amyloid fibrils at a neutral pH. J. Am. Soc. Nephrol. 15, 126-133. doi: 10.1097/01.ASN.0000103228.81623.C7

Zeng, Y., Waters, M., Andrews, A., Honarmandi, P., Ebong, E. E., Rizzo, V., et al. (2013). Fluid shear stress induces the clustering of heparan sulfate via mobility of glypican-1 in lipid rafts. Am. J. Physiol. Heart Circ. Physiol. 305, H811-H820. doi: 10.1152/ajpheart.00764.2012

Conflict of Interest Statement: RK has patent and royalty interests in compounds that interfere with HS:amyloidogenic protein interactions as potential antiamyloid therapies, and patent interests in SAA related peptides that have anti-atherogenic properties.

The reviewer $\mathrm{LB}$ and handling Editor declared their shared affiliation, and the handling Editor states that the process nevertheless met the standards of a fair and objective review.

Copyright (C) 2016 Kisilevsky, Raimondi and Bellotti. This is an open-access article distributed under the terms of the Creative Commons Attribution License (CC BY). The use, distribution or reproduction in other forums is permitted, provided the original author(s) or licensor are credited and that the original publication in this journal is cited, in accordance with accepted academic practice. No use, distribution or reproduction is permitted which does not comply with these terms. 